Buoyancy Effects in Fluids. By J. S. Turner. 1980. Cam bridge Monographs on Mechanics and Applied Mathematics. 368 pages. $\$ 17.95$. Paperbound. Cambridge University Press, 32 East 57th St., New York, N.Y. 10022.

Turner's book, originally published in 1973, is already a standard work in this field, and the appearance of a paperback edition is most welcome. It is concerned with the physics of the entire range of phenomena dominated by stratification, both stable and unstable, examples of which occur ubiquitously both in the atmosphere and the ocean. The influence of the earth's rotation is hardly mentioned-the scales are generally such that the Rossby number is largeand many meteorologists, accustomed to considering stratification as such a strong constraint that it ensures simply that large-scale motions are in essence horizontal, may be astonished at the variety of buoyancy-related phenomena. Of course there are not only internal waves-and these are given their due-but also internal hydraulic jumps, gravity currents, blockage phenomena, and upstream wakes. Turner also discusses turbulence in stratified fluids, plumes, thermals, and turbulent gravity currents, as well as the more classical convection problems between horizontal plates and above a horizontal surface.

Perhaps the most interesting sections of the book are those on mixing across density interfaces such as atmospheric inversions or the oceanic thermocline, internal mixing processes, and (for the oceanographer) double-diffusive convection. Turner and his coworkers have contributed substantially in these areas, and his accounts of them are characterized by care and deep physical insight. The emphasis here is on the synthesis and interpretation of experiments using theory only as a guide-the development of a coherent theory is still some way off. A notable part of the book is the collection of excellent photographs illustrating many of these phenomena, giving a much better appreciation and "feel" than pages of description. The bibliography is extensive.

There is no doubt that this book should be in the personal library of every dynamical meteorologist and oceanographer. With the appearance of the paperback edition, there is no reason why it should not be.-Owen M. Phillips

Owen M. Phillips is Decker Professor of Science and Engineering at Johns Hopkins University in Baltimore, Md.

0003-0007/80/091044-01\$04.25

(C) 1980 American Meteorological Society
Environmental Instrumentation. By Leo J. Fritschen and Lloyd W. Gay. 1979. 216 pages. \$22.80. Hardbound. SpringerVerlag.

Over the past two decades, environmental measurements have increased significantly in the fields of agronomy, ecology, forestry, biology, and atmospheric pollution. Within each of these scientific fields short- and long-term environmental measurements play an important part in correlating and modeling atmospheric effects. As correlations are made and models formulated, the significance of data accuracy and estimates of error increases when attempting to define correlation or model error limits. Hitherto only a few books, such as Meteorological Instruments by Middleton and Spilhaus and the Handbook of Meteorology by Berry, Bollay, and Beers, have been available to the environmental scientist or engineer. Fritschen and Gay have assembled a text on meteorological instrumentation that approaches directly the basic theory of environmental variables and transducers. The text reports their experiences on methodology and use of atmospheric sensors and data recording instrumentation. Throughout the text and within each chapter the appropriate conversion and correction tables are given. Included also are psychrometric, saturation vapor pressure, thermal emf, and many other tables associated with the particular subject being discussed.

The text's contents cover nine subjects with a chapter devoted to each. The chapters are arranged in a logical progression. Environmental measurements and physical fundamentals are treated in the first two chapters. Subsequent chapters treat the atmospheric variables: temperature, soil heat flux, radiation, humidity and moisture, wind speed and direction, pressure, and data acquisition concepts. The first chapter introduces the reader to measurement fundamentals, measurement errors, method of estimating measurement error, measurement systems, and a discussion of significant digits. Chapter 2 reviews the physical fundamentals of environmental measurements, including discussions of thermal and latent energy, basic dc circuits, and basic measuring instrumentation. Chapter 3, Temperature, begins with a discussion of temperature scales and their relation to reference points, and of time constants of sensors exposed to the environment. The authors then follow with a description of temperature measuring devices and their exposure in the air and soil. Chapter 4, Soil Heat Flux, treats soil heat flux transducers, measurements, sampling requirements, and calibration of the heat flux sensors. Chapter 5, Radiation, covers the various radiation wave-length bands, methods of measurement, instrumentation, instrument calibration, site requirements, and photometry. Chapter 6, Humidity and Moisture, treats the fundamental concepts and definition of humidity and moisture, and the methods of measurement

0003-0007/80/091044-02\$04.50

(C) 1980 American Meteorological Society 
and calibration. Chapter 7, Wind speed and Direction, discusses the various sensors and instrumentation used to measure and record these two atmospheric variables; siting of the wind speed and direction sensors also is discussed. Chapter 8, Pressure, covers the types of pressure sensing instruments, measurement units, and corrections for temperature and gravity. Chapter 9, Data Acquisition Concepts, describes signal characteristics, digital acquisition systems, sampling considerations, and signal-to-noise problems within the sampling system. All chapters are well referenced, and the first five chapters have an additional bibliography.

All in all, Fritschen and Gay's Environmental Instrumentation would be an excellent text for graduate and undergraduate meteorological instrumentation courses supplemented with a broader spectrum of environmental instrumentation in use today. The only negative comment I can make with regards to this text is that it does not include a larger sample of present-day environmental instrumentation such as rain gages, visibility measuring instruments, ceilometers, rawinsondes, and aircraft sensors with associated electronics and recording for atmospheric and cloud sampling. This text, as it stands, will be an asset to all concerned with atmospheric measurements and should be a part of every environmental scientist's and engineer's library.-James $\boldsymbol{H}$. Meyer

James H. Meyer is a member of the senior staff at Johns Hopkins University, Applied Physics Laboratory, Laurel, Md.

The New York Summer Aerosol Study, 1976. Edited by Theo. J. Kneip and Morton Lippman. Annals of the New York Academy of Sciences, Volume 322. 165 pages. $\$ 30.00$. Hardbound. New York Academy of Sciences, 2 East 63rd St., New York, N.Y. 10021.

The articles in this volume, describing the methods, data, and conclusions of the New York Summer Aerosol Study (NYSAS) 1976, were presented at a joint meeting of the Section of Environmental Sciences and the Section of Atmospheric Sciences of the New York Academy of Sciences on 20 April 1977.

The NYSAS was undertaken as a cooperative effort between several interested research groups in the New York area. The objective of the study was to characterize the chemistry and physics of the aerosol in the New York urban area as had been done earlier in Los Angeles and St. Louis (ACHEX and RAPS, respectively). An effort was made to determine if there are differences in aerosol properties in urban New York, when compared to Los Angeles or St. Louis, due to differences in geography, climate, emissions, background air chemistry, and long-distance transport. The study took place at two locations-the New York University Medical Center in central New York City and at a rural site $\sim 100 \mathrm{~km}$ northwest of the city where aerosol samples representative of background conditions in the northeastern United States could

0003-0007/80/091045-01\$04.25

(C) 1980 American Meteorological Society be obtained. The study took place during August 1976 with some experiments beginning before or continuing after that month. The 10 papers in the volume describe experimental methods and data. They cover measurements of particle mass concentration, particle size distribution, particle chemistry, aerosol extinction and scattering coefficients, air trajectory, and meteorological parameters. The particle chemistry measurements include analysis for sulfur, sulfate ion, nitrogen, nitrate ion, ammonium ion, halogen ions, organic compounds, and trace metal elements, many of which were obtained as a function of particle size. The first and last chapters provide an overview of objectives and conclusions of the study.

Many of the conclusions must be qualified by the short sampling period and the lack of some meteorological data, e.g., mixing depth. The editors and authors are aware of these shortcomings and include them in their discussion and analysis. A major general conclusion drawn from the study was that the sources and production mechanisms for particles in the $0.1-1.0 \mu \mathrm{m}$ size range are regional in nature. Local sources and photochemical production mechanisms are masked by larger-scale phenomena and transport to the New York urban area. There were no diurnal peaks of submicrometer particle mass concentration. It is estimated that the majority $(73 \%)$ of the observed particulate sulfate mass was from background transport as was a large fraction $(35 \%)$ of the total suspended particulate mass.

There is variability in the content and quality of the chapters. Often, too much reliance is made on statistical correlations of the data and too little physical understanding of the aerosol chemistry is exhibited. However, at least one author recognizes and states the primary usefulness of correlations as an indicator of strong links in the data and areas for further investigation. There are not an unusual number of errors (typographical and otherwise) and omissions, but they can lead to some confusion without a good knowledge of the field and a second reading. The equipment description contains a considerable number of brand names and colloquial jargon. What, for example, is a Charlson Nephelometer?

The volume presents a readable series of research papers that are integrated well and would be of interest to professionals and graduate students in the field of atmospheric chemistry. The editors and authors are to be commended for their experimental efforts and for the timely publication of a collection of concise, comprehensive reports.-David $S$. Covert

David S. Covert is an Assistant Professor in the Department of Environmental Health at the University of Washington, Seattle.

Symposium on Forest Meteorology. By the World Meteorological Organization. W. E. Reifsnyder, Symposium Director. 1979. 234 pages. $\$ 10.00$. Paperbound. Published by the Canadian Forestry Service, Ottawa. Available from UNIPUB, 345 Park Ave. S., N.Y. 10010.

This volume contains the proceedings of a symposium on forest meteorology sponsored by the World Meteorological Society and hosted by the Canadian Forestry Service and the 
Atmospheric Environment Service of the Canadian Department of Fisheries and the Environment. It was held from 21-25 August 1978 at the University of Ottawa, Ontario.

A need currently exists for a state-of-the-art synthesis in the area of forest meteorology, particularly because of the possible effects of deforestation and forest management practices on climate. This symposium proceedings cannot be considered a true synthesis, but it does present current and useful information in the following areas: relationships between climatic factors and forest development and production; the role of forests and wildlands in balances of carbon dioxide, water vapor, and heat on local, regional, and global scales; relationships between meteorology and forest fire, disease, and insect management; energy budgets of forests; wind and light in the forest; and forest meteorology in the tropics.

The latter topic is especially important since little information is available on the meteorology of tropical forests. Most information on forest meteorology comes from northern temperate forests. Tropical forests, however, are being cleared rapidly, and this clearing may contribute greatly to changes in global $\mathrm{CO}_{2}$ levels and potential climatic change. A short but well-written paper by R. W. Furman (pp. 181-197) on this topic is useful, particularly because it includes 99 references. Some data from Southern Hemisphere forests also are included in the volume.

Many new techniques are discussed in the proceedings, including the use of simulation models and computer technology. Especially notable is the discussion of the use of microprocessor technology for the determination of turbulent fluxes of heat, water vapor, and momentum in real time, particularly in remote areas.

Many of the papers are well written, and the selection published here provides an interesting mix ranging from nontechnical to technical. However, the papers are extremely uneven in length, and some are only abstracts. Some are missing entirely. Particularly unfortunate is the absence of the paper on reconstructing climatic variation using tree ring analysis.

The publication is, for the most part, an offset reproduction of typescripts submitted by the authors, which contributes to the variation in style and length. There are many typographical errors, and in some cases authors' affiliations are missing from the papers. The papers could have been improved considerably with just a small degree of editing, especially for grammar and style.

Several recommendations arose from the meeting, including an urging that national meteorological services become more involved in forest meteorology and that more work be conducted in tropical forest meteorology. In general, the volume contains useful information for researchers and teachers in forest meteorology.-Robert L. Edmonds

Robert L. Edmonds is an Associate Professor in the College of Forest Resources at the University of Washington, Seattle.

0003-0007/80/091045-02\$04.50

(C) 1980 American Meteorological Society

\section{new publications}

Atmospheric Physics (Julio V. Iribarne and Han-Ru Cho, 1980, 212 pp., $\$ 15.95$, hardbound, from D. Reidel) "is an introductory textbook on the terrestrial atmosphere and is recommended for second and third year university courses." The book requires only elementary mathematics and introductory physics and "can be used in two ways. Firstly, a general survey of atmospheric physics is provided for students who work or plan to work in other fields ... . but are interested in acquiring general information about atmospheric physics. Secondly, this book will serve as a general and elementary introduction for students who will later specialize in some area of atmospheric science." Each chapter concludes with a list of questions and problems. Chapter titles are: General Description of the Atmosphere; Atmospheric Chemistry; Radiation; Atmospheric Thermodynamics and Vertical Stability; Cloud Physics; Atmospheric Electricity; and Atmospheric Dynamics.

A uroral Processes (C. T. Russell, Ed., 1979, Advances in Earth and Planetary Sciences 4, Special Issue of Journal of Geomagnetism and Geoelectricity, 262 pp., n.p., hardbound, from Conter for Academic Publications Japan and Japan Scientific Societies Press through ISBS) "is based on data and discussions presented at the Third General Scientific Assembly of the International Association of Geomagnetism and Aeronomy; held in Seattle, Washington, August 22 to September 3, 1977. The volume consists of four sessions devoted to different aspects of auroral processes. The sessions are entitled: Timing of Substorm Events; Electromagnetic and Electrostatic Instabilities on Auroral Field Lines; Rapid Auroral Fluctuations and Associated Phenomena; and Mechanisms for the Formation of Auroral Structures."

Benzene Emissions from Maleic Anhydride Plants; Proposed Regulation (Environmental Protection Agency, 1980, 9 pp., n.p., paperbound, from Environmental Protection Agency, Office of Air Quality Planning and Standards, Research Triangle Park, N.C. 27711).

Deformation of the Marine Inversion and the Development of Marine Fog and Stratus Resulting from Warm Water Patches: Numerical Modeling and Verification with Satellite Imagery (C. William Rogers and James T. Hanley, 1980, NAVENVPREDRSCHFAC CR 80-01, 32 pp., n.p., paperbound, from NTIS).

Disasters and the Mass Media (National Academy of Sciences, 1980, 301 pp., \$9.75, paperbound, from NRC/NAS) contains the proceedings of the Committee on Disasters (National Research Council) and the Mass Media Workshop held in February 1979 in Washington, D.C. Main section headings are: A Review of the State of the Art in Disaster Reporting; International Perspectives; National and Local Perspectives; Disaster Warning, Disaster Relief, and the Mass Media; Media Disaster Reporting: Positives and Negatives; and Research Needs and Applications. 
Disasters. The Anatomy of Environmental Hazards (John Wittow, 1980, 411 pp., $\$ 18.95$, hardbound, from University of Georgia Press, Athens, Ga. 30602) “is an attempt not only to summarize the disasters which have caused such widespread death and destruction, but also to explain, as far as possible, why they occur and to discover whether man is partly to blame. In addition, an effort has been made to show some of the ways in which man can predict the events and also alleviate their effects. Such an investigation has revealed that in the world's developing countries the poorer people are becoming more disaster-prone, whilst the developed world has, in many instances, cushioned itself against some of the worst hazards." Main chapter headings include: Subterranean Stress; Surface Instability; The Restless Atmosphere; and Will We Ever Learn?

EPA Publications Bibliography Quarterly Abstract Bulletin (Environmental Protection Agency, 1979, NTISUB/E/042-04, 444 pp., $\$ 15.00$, paperbound, from NTIS).

A Handbook on the Use of Trees as an Indicator of Wind Power Potential (E. W. Hewson, J. E. Wade, and R. W. Baker, 1979, Final Report, RLO-2227-79/3, UC-60, 21 pp., $\$ 6.00$ paperbound, $\$ 3.00$ microfiche, from NTIS).

Health and Environmental Effects of Acid Rain-An Abstracted Literature Collection 1966-1979 (N. S. Dailey and S. G. Winslow, 1980, NLM/TIRC-80/1, 202 pp., \$15.00, paperbound, from F.A.S.E.B., Special Publications, 9650 Rockville Pike, Bethesda, Md. 20014).

The International Turbulence Comparison Experiment (Australia, 1976)-Micrometeorological Support Data (J. R. Garratt et al., 1979, Division of Atmospheric Physics Technical Paper No. 37, 23 pp., n.p., paperbound, from Commonwealth Scientific and Industrial Research Organization, 6th Floor, 372 Albert St., East Melbourne, Victoria 3066, Australia).

Investigation of the Hydrodynamics of Inlet Plume (A. J. Mehta and T. A. Zeh, 1979, NOAA-79122613, PB80-143555, 9 pp., $\$ 5.00$, paperbound, from NTIS).

Light Scattering by Irregularly Shaped Particles (Donald W. Schuerman, Ed., 1980, 334 pp., \$39.50, hardbound, from Plenum) contains most of the invited papers presented at a workshop held at the State University of New York at Albany in June 1979. "Over seventy participants representing many disciplines convened to define some of the ever increasing number of resonant light-scattering problems associated with particle shape and to relate their most recent investigations in this field." Main chapter headings include: User Needs; Specific Particle Descriptions; Theoretical Methods; Experimental Methods; Experimental Results; and Inversion and Information Content.

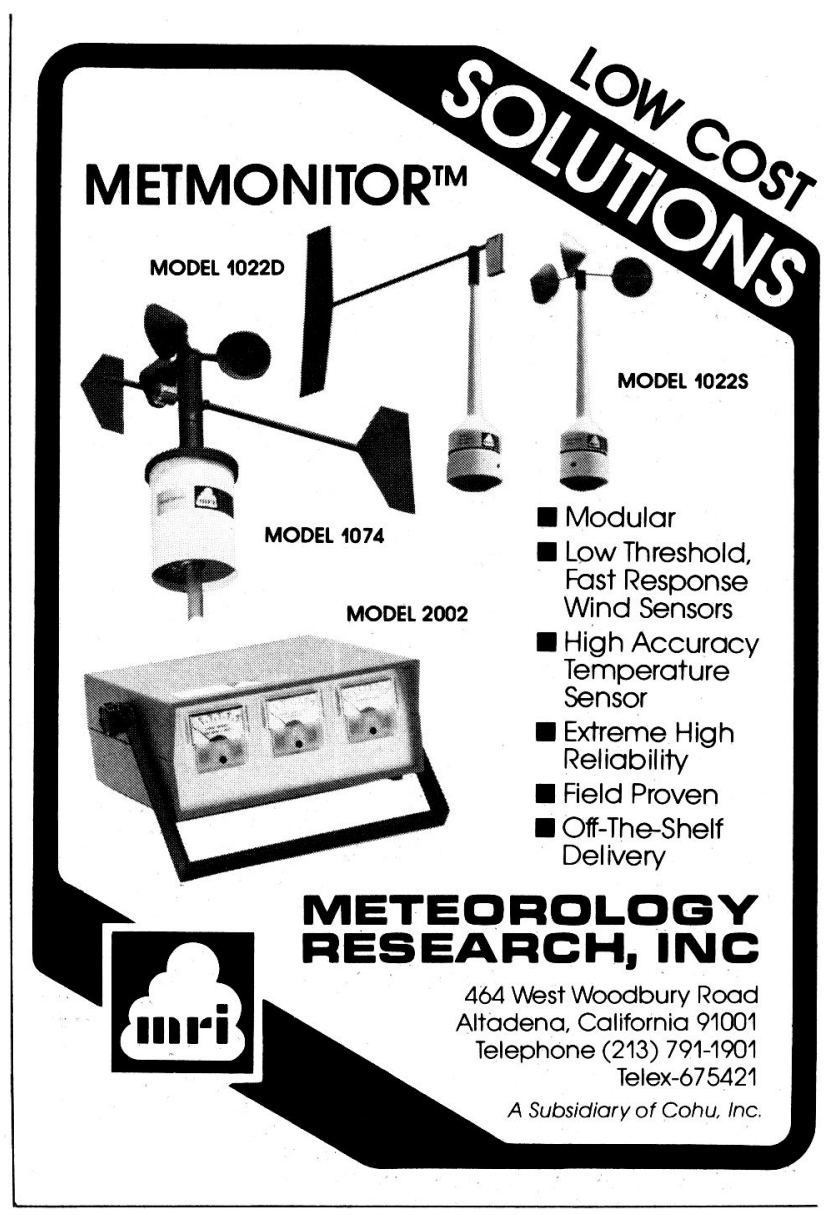

Meteorology: The Atmosphere in Action (Joe R. Eagleman, 1980,384 pp., \$17.95, hardbound, from D. Van Nostrand Company, 135 West 50th St., New York, N.Y. 10020) is intended as an introductory text for students with little physical science background and who do not plan to continue to study meteorology. "Mathematics is not emphasized or required. Appropriate equations are provided, in an optional format, for more mathematically oriented beginning courses." The book deals with such subjects as hail, blizzards, lightning, and tornadoes, and is "designed not only to give the student fuller appreciation of our atmospheric environment but also to provide guidance for dealing with the hazards associated with atmospheric storms." Chapter titles include: Survey of the Atmosphere; Weather Observations, Synoptic Charts, and Forecasts; Radiation and Atmospheric Heat Exchange; Horizontal Winds; Clouds, Precipitation, and Fog; Hurricanes and Tropical Cyclones; Weather Modification; Atmospheric Optics and Acoustics; Air Pollution Meteorology; and Climatology.

The Middle Atmosphere as Observed from Balloons, Rockets and Satellites (The Royal Society of London, 1980, 268 pp., $\$ 25.75$, hardbound, from the Royal Society, 6 Carlton House Terrace, London, England SWIY 5AG) "contains papers presented at a two-day Discussion Meeting held on 12 and 13 December 1978 at the Royal Society. These papers are divided almost equally between studies of middle atmosphere 


\section{Atmospheric Physics}

\author{
J. V. IRIBARNE and H.-R. CHO
}

1980, xii +212 pp.

Cloth Dfl. 40,- / US \$ 15.95

ISBN 90-277-1033-3

Atmospheric Physics is an introductory textbook on the terrestrial atmosphere and is recommended for second and third year university courses. The book requires only the basic understanding of mathematics and such knowledge of physics as can be gained in most first year general physics courses. It provides a general survey of atmospheric physics for students who work or plan to work in other related fields such as geophysics, environmental sciences, etc., as well as serving as a general and elementary introduction for students who will later specialize in some area of atmospheric science.

\section{Now in paperback}

\section{Microphysics of Clouds and Precipitation}

\author{
HANS R. PRUPPACHER and JAMES D. KLETT
}

1978, reprinted 1980, xv $+714 \mathrm{pp}$.

Paper DfI. 40,- / US \$ 19.95

ISBN 90-277-1106-2

Cloth Dfl. 85,- / US \$ 44.75

ISBN 90-277-0515-1

'There is little doubt that this impressive book will be of central importance to cloud physicists and scientists working in related fields.' Nature 'This book no doubt will become a landmark in the realm of cloud physics, not only as an advanced textbook but also as a valuable reference. Its pages contain about as complete an exposition of current knowledge of the subject as one would hope to find anywhere.' Bulletin of the American Meteorology Society

\section{Reidel \\ Publishing Company}

P.O. Box 17, 3300 AA Dordrecht, Holland 190 Old Derby St., Hingham, MA 02043, U.S.A. structure and dynamics, and observations of middle atmosphere composition and chemical reactions. Almost half of the papers are based on satellite-borne remote-sensing measurements since a wide coverage in space and time of observations is required. In this respect, the volume points the way for future developments as well as providing a review of the present knowledge and understanding of the middle atmosphere."

1979 Status Report-The Sierra Cooperative Pilot Project Precipitation Management Research in the Sierra Nevada (U.S. Department of the Interior, 1979, 70 pp., n.p., paperbound, from NTIS).

The North-West European Shelf Seas. Vol. 2: Physical and Chemical Oceanography, and Physical Resources (F. T. Banner, M. B. Collins, and K. S. Massie, Eds., 1980, Elsevier Oceanography Series, 24B, 400 pp., n.p., from Elsevier) is the second part of a "two-volume interdisciplinary synthesis of our current knowledge of the nature of the sea bed, sediments and seawaters of the Northwestern European Continental Shelf [and] includes accounts of the physical resources and problems associated with the socio-economic development of the area. Many chapters introduce evaluations and assessments of new data which are used both to clarify the regional patterns and to exemplify particular processes and phenomena. The text is accompanied by numerous illustrations and extensive, up-to-date reference lists." Volume 2 chapter titles include: Tides on the North-West European Continental Shelf; Wave Climatology of the U. K. Continental Shelf; Sediment Transport by Waves and Tides: Exemplified by a Study of Swansea Bay, Bristol Channel; Physical and Dynamical Oceanography of the Irish Sea; and Socio-Economic Development and Management of Coastal Zones. Volume 1 of this set is entitled Geology and Sedimentology.

Oceanographic Atlas of the Bering Sea Basin (Myron A. Sayles, Knut Aagaard, and L. K. Coachman, 1980, 170 pp., $\$ 15.00$, hardbound, from University of Washington Press, Seattle, Wash. 98105) was drawn from "all available hydrographic information from the Bering Sea Basin" from which the authors "have computed and drawn a wide range of oceanographic variables. These include averaged horizontal and vertical sections of temperature and salinity, detailed volumetric temperature-salinity correlations, dynamic heights of various surfaces, seasonal salt and heat content of standard sections, core characteristics, and others." The atlas includes "one hundred charts, including numerous color foldouts, with accompanying tables and text. . . A new cartographic technique is included in the atlas, based on computer-drawn perspective views of the volumetric distributions."

The Ozone Layer (Asit K. Biswas, 1979, Environmental Sciences and Applications, Vol. 4, 381 pp., \$50.00, hardbound, from Pergamon) contains the proceedings of the Meeting of Experts Designated by Governments, Intergovernmental, and Nongovernmental Organizations on the Ozone Layer Orga- 
nized by the United Nations Environment Program in Washington, D.C., during March 1977. Paper titles include: Environmental Aspects of Stratospheric Ozone Depletion; Effects of Ultra-violet Radiation on Human Health; Atmospheric Ozone-A Survey of the Current State of Knowledge of the Ozone Layer; Protection of the Ozone Layer-Some Economic and Social Implications of a Possible Ban on the Use of Fluorocarbons; Atmospheric Exchange Processes and the Ozone Problem; and A Review of the Industry-Sponsored Research into the Effects of Chlorofluorocarbons on the Concentration of Atmospheric Ozone.

Pike-Buchanan Flash Floods of July 15, 1979 (National Weather Service, 1979, NOAA-79122603, PB80-143605, 27 pp., $\$ 6.00$ paperbound, $\$ 3.50$ microfiche, from NTIS).

Pollution and Reform in American Cities, 1870-1930 (Martin V. Melosi, Ed., 1980, 224 pp., \$15.00, from University of Texas Press, Box 7819, Austin, Tex.) may be of historical interest to some Bulletin readers. The eight essays in the book "take a critical look at the 'First American Environmental Crisis,' as well as the response of early reformers to it." The book provides "an analysis of the social and political impact of environmental problems during a time when the United States was making the important transition from a rural, agrarian society to an urban, mechanized nation. Rather than accept pollution as a necessary evil of 'progress' and industrialization, public health officials, sanitation engineers, biological scientists, journalists, women's groups, and others sought to raise public consciousness of the declining quality of life in American cities. Their actions, in turn, laid the foundations for similar concerns by environmental groups today, whose members often encounter identical resistance." Essays include: The Battle for Clean Air: The Smoke Problem in Post-Civil War America; Environmental Crisis in the City: The Relationship Between Industrialization and Urban Pollution; and Pollution and Political Reform in Urban America: The Role of Municipal Engineers, 1840-1920.

Precipitation Sample Handling, Analysis, and Storage Procedures (Mark E. Peden, Lorretta M. Skowron, and Florence M. McGurk, 1979, DOE Research Report 4, COO-1199-57, 71 pp., n.p., paperbound, from Illinois State Water Survey, Box 232, University of Illinois, Urbana, Ill. 61801).

Report of the Climate Data Management Workshop Held At Harpers Ferry, West Virginia on May 8-11, 1979 (National Oceanic and Atmospheric Administration, 1979, NOAA79112101, PB80-128226, 311 pp., $\$ 17.00$ paperbound, $\$ 3.50$ microfiche, from NTIS).

The Science and Wonders of the Atmosphere (By Stanley David Gedzelman, 1980, 535 pp., \$19.95, hardbound, from Wiley) is an introductory text in meteorology, made espe-

\section{DIRECTOR}

ATMOSPHERIC TECHNOLOGY DIVISION NATIONAL CENTER FOR ATMOSPHERIC RESEARCH

The National Center for Atmospheric Research in Boulder, Colorado seeks applịçations for Director of this division, which develops and provides aircraft, radars, and other research services and facilities to scientists from universities, NCAR and other research groups engaged in atmospheric research. ATD has a technical and scientific staff of about 169 persons and $a$ budget of $\$ 7.5$ million. The ATD director is the technical and administrative leader of the division, responsible for overall planning and operations, and often represents NCAR in field facility planning for major national and international programs. Requires Ph.D. or equivalent in physical science or engineering; broad knowledge of atmospheric research facilities; research experience in the use of such facilities; and demonstrated ability in planning, management, and working cooperatively in the university-federal research community. Please send letter and resume to: Dr. G. W. Curtis, P.O. Box 3000, Boulder, Colorado 80307.

NCAR is an Equal Opportunity/Affirmative Action Employer

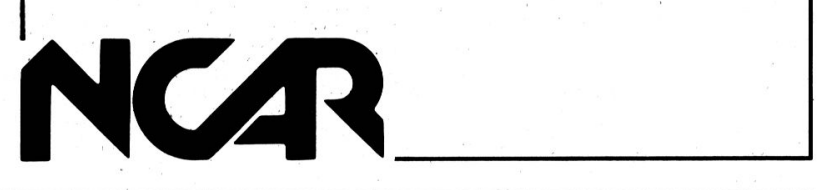

cially comprehensive for those who will take no other atmospheric science courses. The mathematics is extensive but "presented in a straightforward, practical manner," and metric units are used throughout. A partial listing of chapter titles includes: Clouds; Optical Phenomena; The Earth in Space; Air Molecules; the Composition and Evolution of Our Atmosphere and the Rest of the Solar System; Temperatures and Heat; Agricultural Meteorology: The Climate Near the Ground; Water Vapor and the Hydrologic Cycle; Changes in Rising and Sinking Air: Static Stability; Extratropical Highs and Lows; Modern Weather Analysis and Forecasting; Climates Around the World; The Mark of Climate on the Earth; and The Mark of Climate on the Human Race.

Selective Guide to Climatic Data Sources (National Climatic Center, 1979, Key to Meteorological Records Documentation No. 4.11, 142 pp., n.p., paperbound, from Director, National Climatic Center, Federal Building, Asheville, N.C. 28801).

Snow Cover (Marilyn J. Shartran, 1979, NOAA-79120702, PB80-143282, 107 pp., $\$ 9.00$ paperbound, $\$ 3.00$ microfiche, from NTIS).

Solar Energy Technology Handbook (William C. Dickinson and Paul N. Cheremisinoff, 1980, Energy, Power, and Envi- 
ronment Series, Vol. 6; Part A: Engineering Fundamentals: 912 pp., \$85.00; Part B: Applications, Systems Design, and Economics: 848 pp., \$85.00; from Marcel Dekker, Inc., 270 Madison Ave., New York, N.Y. 10016), in two parts, is a "comprehensive, authoritative, and up-to-date reference book on the current state of knowledge of each of the six solar energy technologies . . . solar resource, solar thermal collectors, photovoltaics, bioconversion, wind energy, and solar energy storage systems . . . . and presents the engineering fundamentals of these technologies as well as the necessary working formulas." Part $B$ "focuses on the applications of these technologies as well as the economics of solar systems; the barriers to and incentives for commercialization; and the environmental, health, and safety issues involved in the use of solar energy."

Terrestrial Rare Gases (E. C. Alexander, Jr., and M. Ozima, Eds., 1978, Advances in Earth and Planetary Sciences 3, 229 pp., n.p., hardbound, from Center for Academic Publications Japan and Japan Scientific Societies Press through ISBS) "is based on data and discussions presented at a Joint JapanU.S. Seminar held in Hakone National Park, Japan, from June 28 to July 1, 1977, and examines the constraints that rare gas data place on models of the origin and evolution of the earth's atmosphere. The 18 papers are not, however, restricted to the presentations at the conference. The papers were prepared during the fall of 1977, and the authors had the opportunity to modify their contributions to include the comments and material given at Hakone... three papers from rare gas workers who were unable to attend the Hakone Seminar are included.

Weather Modification by Cloud Seeding (Arnett S. Dennis, 1980, International Geophysics Series, Vol. 24, 267 pp., \$29.50, hardbound, from Academic) "attempts to present a general view of the subject but with the emphasis on physical rather than legal, economic, or sociological aspects. The current state of the art is described, and some promising areas for additional research are pointed out. Underlying the entire book is the author's conviction that the evidence on the effects of cloud seeding can be sifted to yield a coherent picture that is consistent with the laws of atmospheric physics." Main chapter headings include: The Atmospheric Aerosol; The Formation of Clouds and Precipitation; Concepts and Models for Cloud Modification; Generation and Application of Silver Iodide Crystals and Other Seeding Agents; Statistical Evaluation of the Results of Cloud Seeding; The Modification of Fog, Snow, and Rain; Suppression of Weather Modification; and Impacts of Weather Modification on Society.

Wind Energy Systems: Program Summary (U.S. Government, 1979, S/N 061-000-00294-4, 130 pp., \$3.00, from Superintendent of Documents) outlines the projects funded by the Fed- eral Wind Energy program during FY 1978 "and describes the program's general organization and specific elements. . . . The objective of the Federal Wind Energy program is to accelerate the development of reliable and economically viable wind energy systems and enable the earliest possible commercial use of wind power."

Academic Press, Inc., 111 Fifth Ave., N.Y., N.Y. 10003

Ann Arbor Science Publishers, Inc., P.O. Box 1425, Ann Arbor, Mich. 48106

Electric Power Research Institute, Research Report Center, P.O. Box 10090, Palo Alto, Calif. 94303

Elsevier Scientific Publishing Co., P.O. Box 211, Amsterdam, The Netherlands; for U.S. and Canadian customers, Elsevier Publishing Co., 52 Vanderbilt Ave., New York, N.Y. 10017

G. K. Hall \& Co., 70 Lincoln St., Boston, Mass. 02111

Halsted Press, Div. of John Wiley and Sons, Inc., 605 Third Ave., New York, N.Y. 10016

ISBS, Inc., P.O. Box 555, Forest Grove, Oreg. 97116.

National Academy of Sciences/National Research Council, Printing and Publishing Office, 2101 Constitution Ave., N.W., Washington, D.C. 20418

National Technical Information Service, U.S. Dept. of Commerce, 5285 Port Royal Rd., Springfield, Va. 21151

Pergamon Press, Maxwell House, Fairview Park, Elmsford, N.Y. 10523; (overseas) Pergamon Press, Ltd., Headington Hill Hall, Oxford, OX3 OBW, U.K.

Plenum Publishing Corp., 227 w. 17th St., New York, N.Y. 10011

Prentice-Hall, Inc., Englewood Cliffs, N.J. 07632

D. Reidel Publishing Co., 160 Old Derby St., Hingham, Mass. 02043

Springer-Verlag, 175 Fifth Ave., New York, N.Y. 10010

Superintendent of Documents, U.S. Government Printing Office, Washington, D.C. 20402

UNIPUB, 345 Park Ave. South, New York, N.Y. 10010

John Wiley and Sons, Inc., 605 Third Ave., New York, N.Y. 10016 


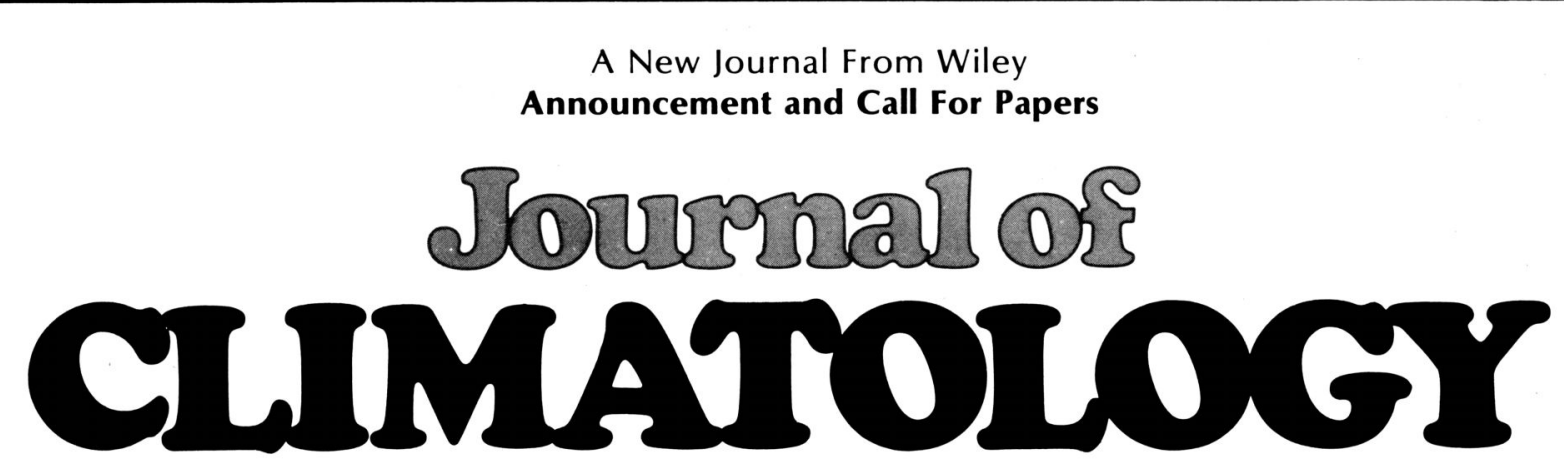

\title{
A Journal of the Royal Meteorological Society
}

\author{
Editor \\ Professor S. Gregory \\ Department of Geography, \\ The University, Sheffield S10 $2 T \mathrm{~N}$
}

\begin{abstract}
Aims and Scope
Papers dealing with climatological problems are widely dispersed in the literature of meteorology, hydrology, geography and ecology. There is a need for an international journal to span the whole expanding field of climatology and the Journal of Climatology has been launched to satisfy this need through the quarterly publication of research papers, major reviews of progress and reviews of new books and reports. Its main role will be to report and stimulate research in climatology, and the Journal will encompass global and regional studies of climate, local and microclimatological investigations, changes of climate (past, present and future), and the application of climatological knowledge to a wide range of human activities.
\end{abstract}

\section{Editorial Board}

Professor R. Ananthrakrishnan

Indian Institute of Tropical Meteorology, Ramdurg House, University Road,

Shivajinagar, Poona - 411 005, India.

\section{Professor W. Bach}

Center for Applied Climatology and Environmental Studies, University of Munster, Robert-Koch-Strasse 26, D 4400 Munster, Germany.

\section{* Dr. E.C. Barrett}

Department of Geography, University of Bristol, University Road, Bristol BS8 1SS

\section{Professor R.G. Barry}

Institute of Arctic and Alpine Research, University of Colorado, Boulder,

Colorado 80309, U.S.A.

* Dr. J.A. Clark

Department of Physiology and Environmental Studies, School of Agriculture, University of Nottingham, Sutton Bonington,

Loughborough LE12 5RD

* Dr. J.S.A. Green
Atmospheric Physics Group, The Blackett
Laboratory, Imperial College of Science
and Technology, University of London
London SW7 2AZ.
* Mr. D. Houghton
Meteorological Office, London Road,
Bracknell, Berkshire RG12 2SZ.
Professor T. Kawamura
Laboratory of Climatology, Institute of
Geoscience, University of Tsukaba,
1-1-1-Sakura-Mura, Nihari-Gun,
Ibaragi, 300-31 Japan.
Professor J. Loup
Institut de Geographie Alpine, Universite
scientifique et medicale de Grenoble,
Rue Maurice-Gignoux,
38031 Grenoble, France.
Professor J.S. Oguntoyinbo
Department of Geography,
University of Ibadan, Ibadan, Nigeria.
Professor T.R. Oke
Department of Geography, University of
British Columbia, 2075 Wesbrook Mall,
Vancouver, British Columbia,
Canada V6T 1 W5.

\section{* Dr. J.S.A. Green}

Atmospheric Physics Group, The Blacket Laboratory, Imperial College of Science London SW7 2AZ

* Mr. D. Houghton

Meteorological Office, London Road Bracknell, Berkshire RC12 2SZ.

\section{Professor T. Kawamura}

Laboratory of Climatology Institute of

Geoscience, University of Tsukaba,

1-1-1-Sakura-Mura, Nihari-Gun,

Alpine, Universite

Rue Maurice-Gignoux,

38031 Grenoble, France.

University of Ibadan, Ibadan, Nigeria.

Professor T.R. Oke

Canada V6T 1 W5

\section{Professor J. Oliver}

Department of Geography, James Cook University of North Queensland, Townsville, Queensland 4811, Australia.

Professor J. Paszynski,

Institut Geografie, Polska Akademia Nauk, Krakowskie Przedmiescie 30,

Warszawa, Poland.

\section{Professor D. Sharon}

Physical Geography Section, Institute of Earth Sciences, The Hebrew University of Jerusalem, Jerusalem, Israel.

Professor R.H. Skaggs

Department of Geography, University of Minnesota, 414 Social Sciences Building, 267, 19th Avenue South, Minneapolis, Minnesota 55455, U.S.A.

Professor P.D. Tyson

Department of Geography \&

Environmental Studies, University of Witwatersrand, 1 Jan Smuts Avenue, Johannesburg 2001, South Africa.

*Members of the Editing Committee

Intending Contributors to the early issues are requested to contact Professor Gregory. QUARTERLY STARTING JANUARY 1981

A specimen copy and/or further information are available on request from either of the addresses below.

Journals Department,

John Wiley \& Sons Ltd.

Baffins Lane

Chichester

Suscex PO19 1(1)

Ingland
Subscription Department ' $C$ ' John Wiley \& Sons Inc.

605 Thind tienue

New York

N.Y. 10016

U.S.A. 